\title{
Uncovering the Messages Behind Four Imperial Dragon Robes from Exhibitions With Yin and Yang Message
}

\author{
Shu Hwa Lin, C J Duarte \\ University of Hawaii at Manoa, Honolulu HI, USA
}

\begin{abstract}
The design themes of three Qing dynasty imperial dragon robes from the University of Hawaii at Manoa Costume Collection act as carriers of the Chinese yin-yang philosophy. The information shared by these imperial dragon robes are discussed through a cultural and technological analysis of the symbolic motifs and fabric structures of these garments to reveal the cultural and social impact of yin-yang on Qing imperial costume design.
\end{abstract}

Keywords: Dragon robe, Yin and Yang, imperial/court costume

\section{Introduction}

Since the Qing dynasty (1644-1911), the yin-yang philosophy has been utilized in Chinese court dress (Lin, 2015). The influence of yin-yang on Chinese costume design can be observed in the surviving artifacts of the Qing dynasty (Cheng, 2008; Camman, 1952). The University of Hawaii at Manoa (UHM) Costume Collection (UHMCC) houses three kosse robes (i.e., tapestry) and one embroidery dragon robes from the Qing dynasty which provide representations of the yin-yang philosophy through the motifs and color patterns of its design. These important robes were selected to exhibit during special days such as year of dragon, UHM 100 years, and UHMCC 50 year's anniversary. There are four categories of court dress: gunfu, chaofu, jifu, changfu (Zhoa, 1989; Zhou \& Gao, 1988). Three dragon robes from the UHM Costume Collection are classified as jifu, or semi-formal court robe (Vollmer, 1977a).

In recent years, court robes have been a valuable resource to researchers to explore how the ancient Chinese used textiles to demonstrate political power and social rank, and to reconstruct historical Chinese textile technology (Welch, 2013; Zhou \& Gao, 1988). Some symbols and patterns, based on Qing dynasty court rule, have assigned meaning to indicate a wearer's social status (Vollmer, 1983).

The influence of yin-yang on these kosse dragon robes can be identified by the textile patterns (Tortora \& Merkel, 1996). Here, yin-yang was applied to the robes through the manipulations of colors and weave patterns as well as the symbolic motifs (Lin, 2008, 2013). In imperial costume, the utilization of yin-yang is not purely aesthetic but also points to deep symbolic meaning and the promulgation of cosmic relationships (Lin, 2015).

Yin-yang was originally documented in the Book of Yi, which describes, "everything is in conformity with yin-yang". The Yin-yang philosophy suggests all existence is attributed to binary forces which strive to maintain balance in nature. These forces are commonly represented in terms of complementary opposites such as day/night, sun/moon, cold/hot, truth/falsehood, light/dark, fullness/emptiness and masculine/feminine (Ho,

\footnotetext{
Shu-Hwa Lin, Ph.D., Associate Professor and Costume Curator, Department of Family \& Consumer Sciences, Fashion Design \& Merchandising, University of Hawaii at Manoa.

C J Duarte, Research Assistant, Department of Family \& Consumer Sciences, University of Hawaii at Manoa.
} 
1974). The yin-yang harmony influenced all aspects of Chinese daily life and worldview, and as a result, encouraged an abundance of utilitarian and decorative representations to increase harmony and the awareness of peace.

\section{Yin-Yang Design Theory}

The overall structure of Qing dynasty court dress has evolved very little since ancient China, as seen in the dragon robes from the University of Hawaii at Manoa. These dragon robes are full-length and side-fastening with tapered sleeves and front, rear, and side slits (Lin, 2013). Qing official robes maintain a simple and utilitarian silhouette. As a result, Chinese costume emphasizes textile design by using embellishments such as embroidery, tapestry (kosse), brocade, damask, and painting (Vollmer, 1983; Vollmer, 1977b). It is primarily the design patterns of court dress which has developed over time to reflect dynastical interest in cultural symbology.

Yin-yang balance is achieved in the University of Hawaii at Manoa kosse robes by the organization of the motifs and patterns. Slight color and shape differences are noted in the motifs to subtly suggest the dichotomy of yin-yang forces. To obtain the sense of dichotomy, the design of each side of the garment offers some comparison. For instance, the design is halved by the center front line of the garment structure and distinguished in terms of left and right sides to connote yin or yang. It is also common practice that symbols positioned in the center of the robe will be divided into a yin or yang side.

Color and size variations in the textile pattern and motifs are significant indicators of the yin and yang elements. According to Chinese color theory, light colors are attributed to the yin element while dark colors are attributed to the yang element. Though this relationship can differ depending on the design in which the color is placed and its relationship to surrounding colors. In general, lighter colors and simpler shapes are associated with yin while darker and bolder colors and exaggerated shapes are associated with yang.

Most motifs in the University of Hawaii kosse robes convey yin-yang with a two-color tonal difference in design. For instance, the background of the "yellow" kosse robe is woven entirely with an endless-knot motif with yellow and blue yarns. The yellow and blue colors, as well as the symmetry of the endless-knot pattern, indicate the presence of yin-yang balance.

Chinese folklore and myths also contribute to the designs of court dress (Scott, 1958; Vollmer, 1977b). The motifs of Twelve Symbols of Sovereignty (sun, moon, mountains, three-star constellation, dragons, pheasant, fire, grain, rule, axe, seaweed, and bronze cups) presented on Figure 1 which shown front and back views of dragon robe (Capon, 1970). The completed Twelve Symbols of Sovereignty will apply on for Emperor' robes. Some symbols, such as the lotus, carry multiple meanings and often adopted to many dragon robes (Welch, 2013). In addition, many of the symbols already stand for either yin or yang, such as the sun and moon, respectively. However other symbols may depend on color and size variation in order to hold cosmic significance (Lin, 2013).

Court dress mirrored Qing court hierarchal structure and functioned as outward expressions of the wearer's rank and merits (Michael, 1942). The elaborate decorative elements of official costumes provided esteem to the imperial family and court officials. Meanwhile, the symbolic motifs referenced the dynasty's supremacy in the cosmos. Yin-yang was adopted to court costume design in order to transmit ancient Chinese cultural beliefs as well as honor the imperial connection to the cosmos as the dichotomy of the yin-yang elements was thought to dictate the organization of the universe. 


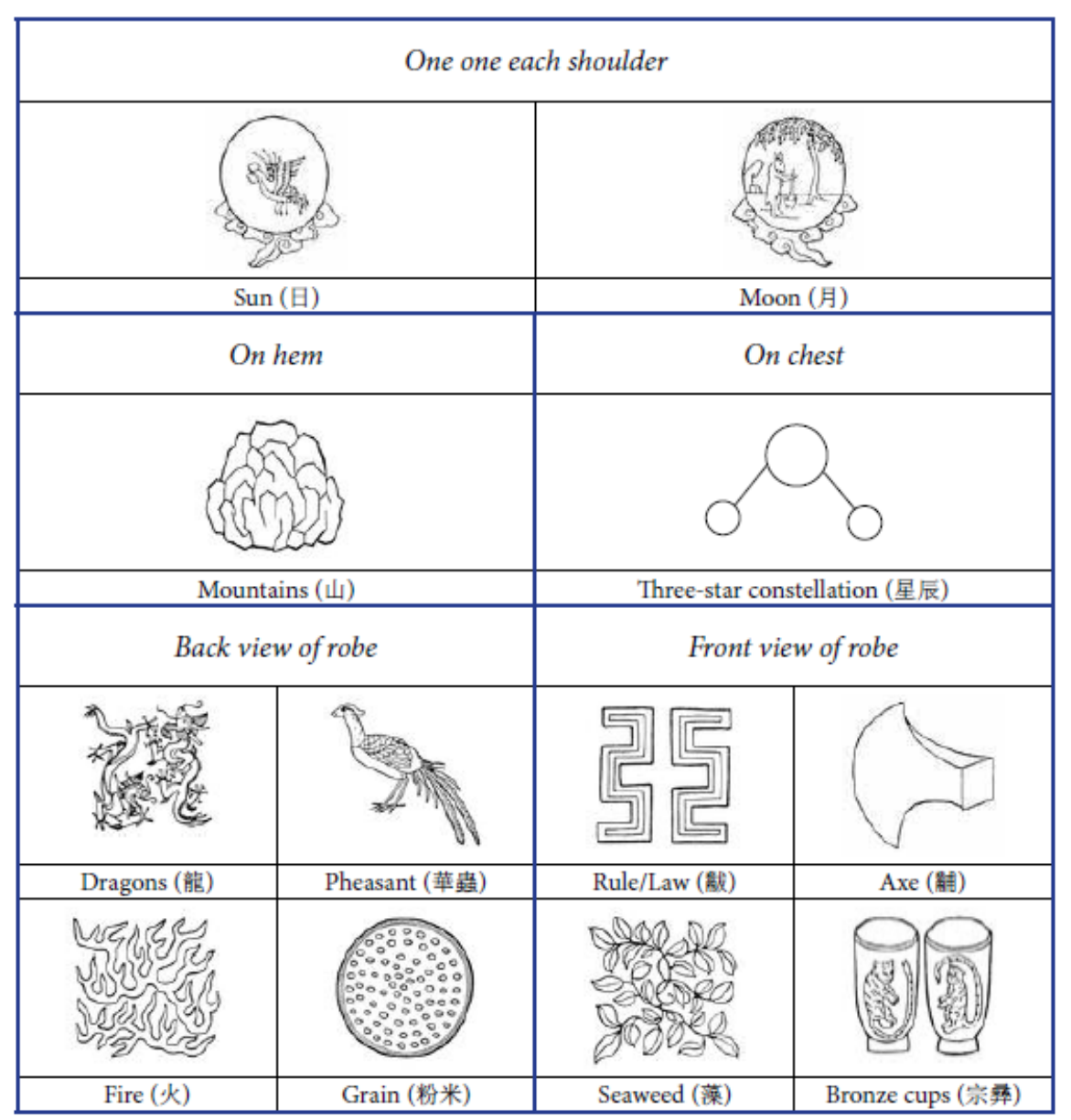

Figure 1. Twelve symbols of sovereignty frequently seen as motifs on dragon robes with their designated locations on the robe.

According to Hall's in the Power Dressing (2006), when a dragon and tiger were symbolized as a pair, the dragon was considered yang and tiger was considered yin. In the Song dynasty, the dragon and tiger symbols were eventually replaced by the taiji diagram. The dragon is the chief Symbol of Sovereignty and has been used in Qing court dress to embody the emperor and the yang principle. According to the Da-Qing-Hui-Dien, regulations were made to reserve the use of five-clawed dragons for the emperor, the heir apparent, and high ranking princes; whereas three- or four-clawed pythons were worn by a Count (or 3rd ranking princes) and below, or by high rank officials (Jackson \& David, 1999) (see Figure 2).

A striking yellow color theme marks the yellow kosse dragon robe from the University of Hawaii Costume Collection. The entire garment is made of highly elaborate kosse weave, except for a small section of yellow satin on the sleeves. The yellow robe is the highest ranking dragon robe in the collection, indicated not only by the yellow color theme, but by the nine five-clawed dragons motif and nine Symbols of Sovereignty present in the design. According to the Da-Qing-Hui-Dien, first-degree princes were permitted to have nine of the Twelve Symbols of Sovereignty adorned on court dress. Yellow was considered the color of earth and belongs to the yin element. It also was the official Qing imperial color traditionally worn by the emperor or prince (Zhou \& Gao, 1988; Shih, 1977; Michael, 1942). No detail of imperial costume was overlooked; the yellow silk-taffeta lining on the interior of the dragon robe further suggests it was intended for a member of the imperial family. 


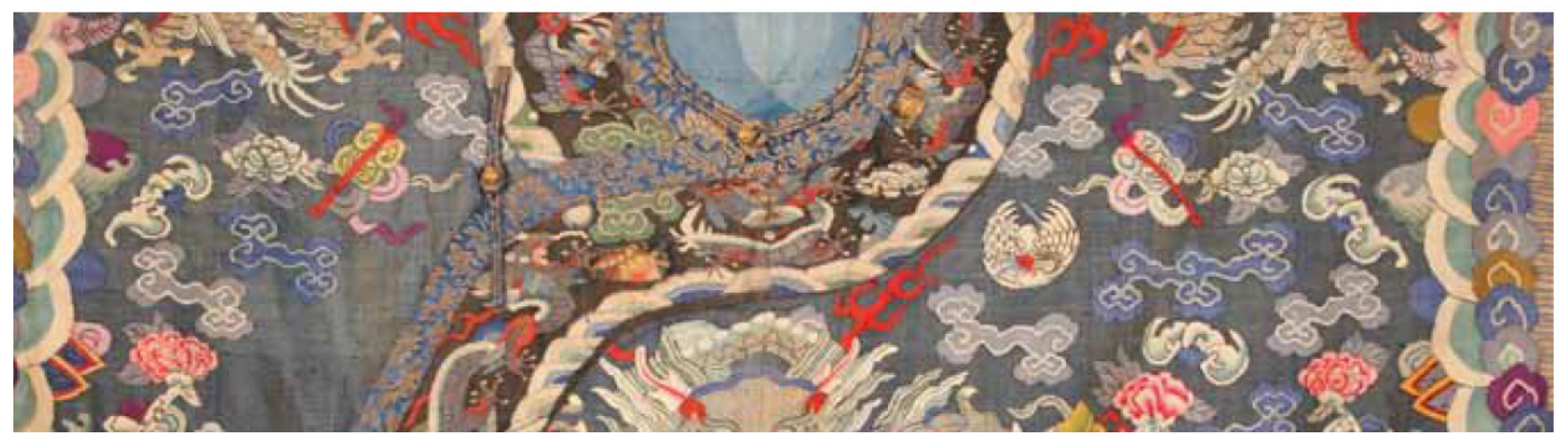

Figure 2. Four-clawed pythons. Picture of Dragon robe is housed University of Hawaii at Manoa Costume Collection.

The yin-yang representations are more subtle in the yellow dragon robe compared to the blue python robe discussed later in the article. Here, yin-yang is primarily emphasized by the blue/yellow endless-knot background and the design differences of the dragon motifs, indicated by slight shape and color variations.

The front-facing dragon motif on the front bodice is divided into halves by the center front line of the robe to designate yin and yang. Three key morphological differences occur in the center front-facing dragon. The two separate color tones (blue/red) of the teeth outlines are the primary indicator of yin-yang. On the left side, the outline is woven with blue yarns, on the right side, the outline is woven with red (see Figure 3). The ears are also distinct; a yellow hook-like shape found in the left ear is entirely absent in the ear on the right. In addition, the flames surrounding the left side of the dragon extend further than the flames on the right. From the difference noted in the flame design, the left side of this dragon may be considered yang while the right side may be considered yin.

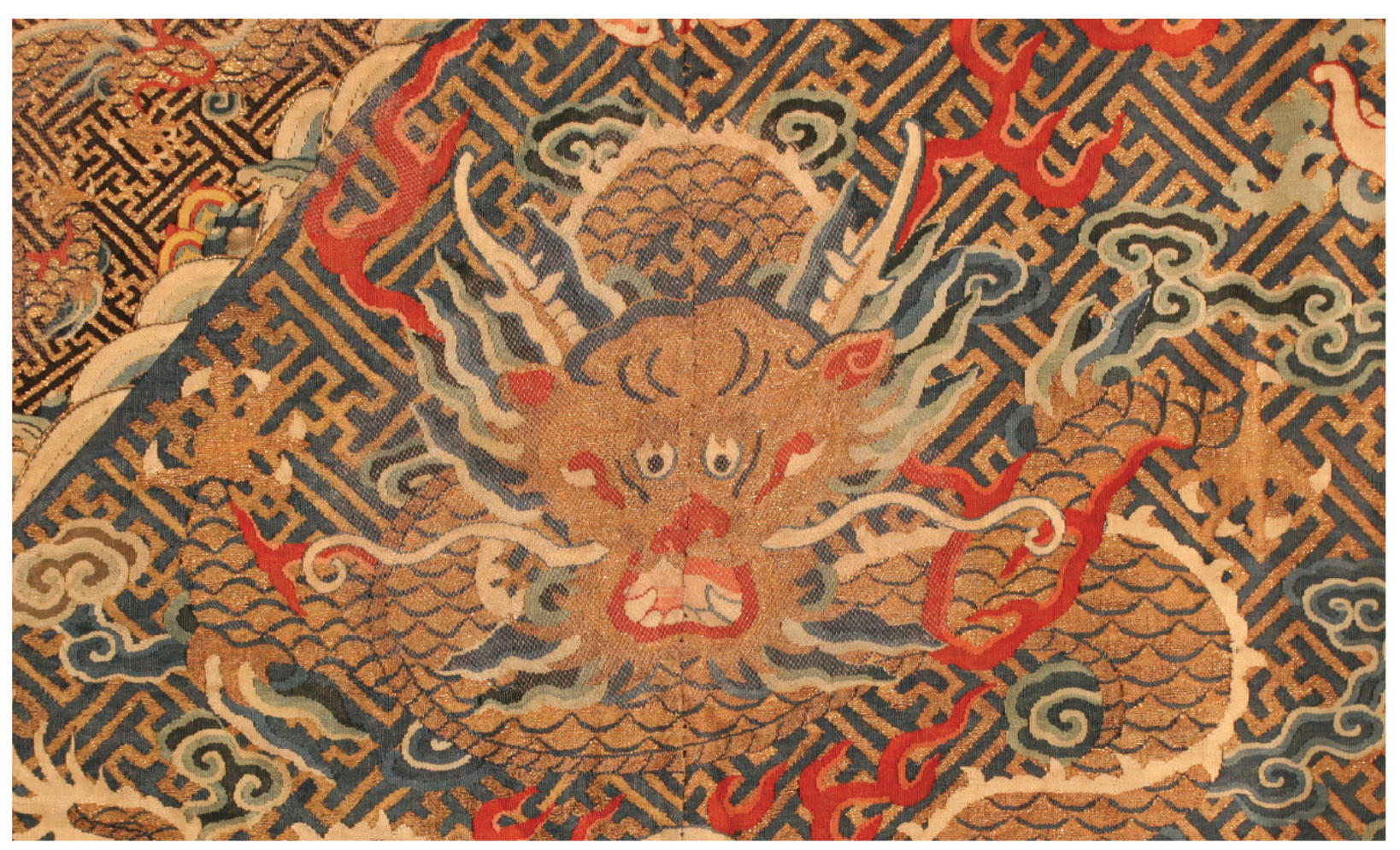

Figure 3. Details of close-up picture of front-facing dragon indicated by two-color tone with yin-yang eyes, lip, tooth, and ears. Picture of Dragon robe is housed University of Hawaii at Manoa Costume Collection. 
The walking dragon motifs on the lower bodice (see Figure 4) also have three areas which show yin-yang complementary. The flames surrounding the left dragon extends further and has longer pink tips then the flames on the other dragon (see Figure 5). The size and shape differences of these flames also suggest yang and yin, respectively. The eyes of the left dragon are half-encircled with blue yarns. The half-encircled outlines represents the eyes wide-open at night and is symbolic of yang. The eyes on the right are fully-encircled with blue yarns. The enclosed outline represents the eyes partially closed or sheltered under the sunlight. The sun or day stands for the yin element. The forehead of both dragon's are decorated with crescent lines which seem to form the appearance of a hooded brow. There are more brow lines on the right dragon than on left. In addition, the crescent of the hooded brow opens to the left on both dragons. Here, the orientation of the brow is reversed. Reversing patterns is a signature of yin-yang design, signifying the opposite and parallel elements.
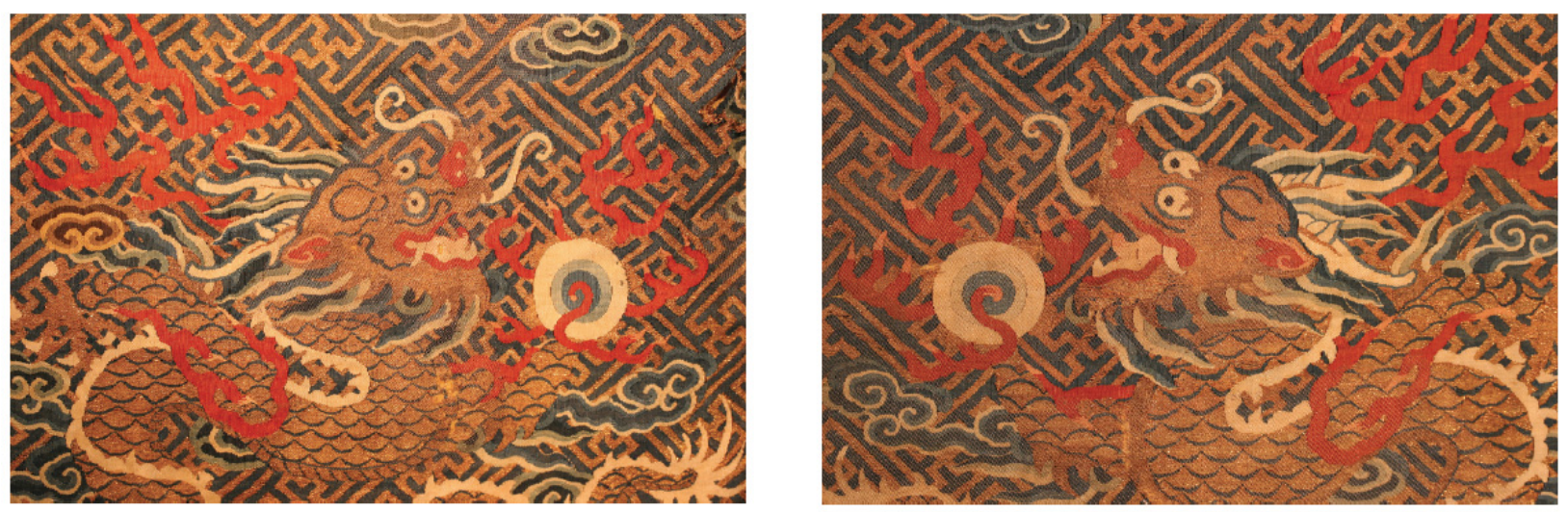

Figure 4. Left-profile walking dragon at left hem and right-profile walking dragon. Picture of Dragon robe is housed University of Hawaii at Manoa Costume Collection.

There are two additional yin-yang complementary motifs near the lower bodice walking dragons. Below the tail of each walking dragon, a millet is described by two color tones. The millet on the right side is outlined with yellow yarn. The millet on the left is outlined with blue. Although the yellow is a yin element, the red pattern inside the grain is darker and more defined than in the millet on the left. Regardless of the yellow (yin) outline, the design of the millet on right is more exaggerated and may represent yang. The flaming pearls near each dragon (see Figure 4) are comprised of three rings of different color tones: white, light blue, and dark blue. The light blue layer on the left side is a slightly lighter shade than the right. Although it is a small difference between the two flaming pearls, the slight shade change in the light blue ring suggests yin-yang.

A pair of fish is separated on either side of the front bodice, suspended just above the wave motif on the bottom hem. These fish mirror each other as reflected images. Yin-yang design favors reflected imagery as it corresponds to balance and symmetry. Each fish motif is depicted with ribbons and a lotus designed in different color-tones to represent yin-yang.

The blue python robe has six five-clawed pythons on the front and rear bodice and three four-clawed pythons on the shoulders and inner flap (see Figure 6). The bodice and sleeve cuffs are kosse with color painting applied to selected motifs to add color gradation and depth to the pattern. The wearer may have received special permission by the emperor to wear the five-clawed python. According to the Da-Qing-Hui-Dien, lower ranking princes and noblemen wore brown, blue or blue black. Therefore, the blue python robe could have belonged a lower ranking prince, nobleman or an official of fourth-rank and below. 


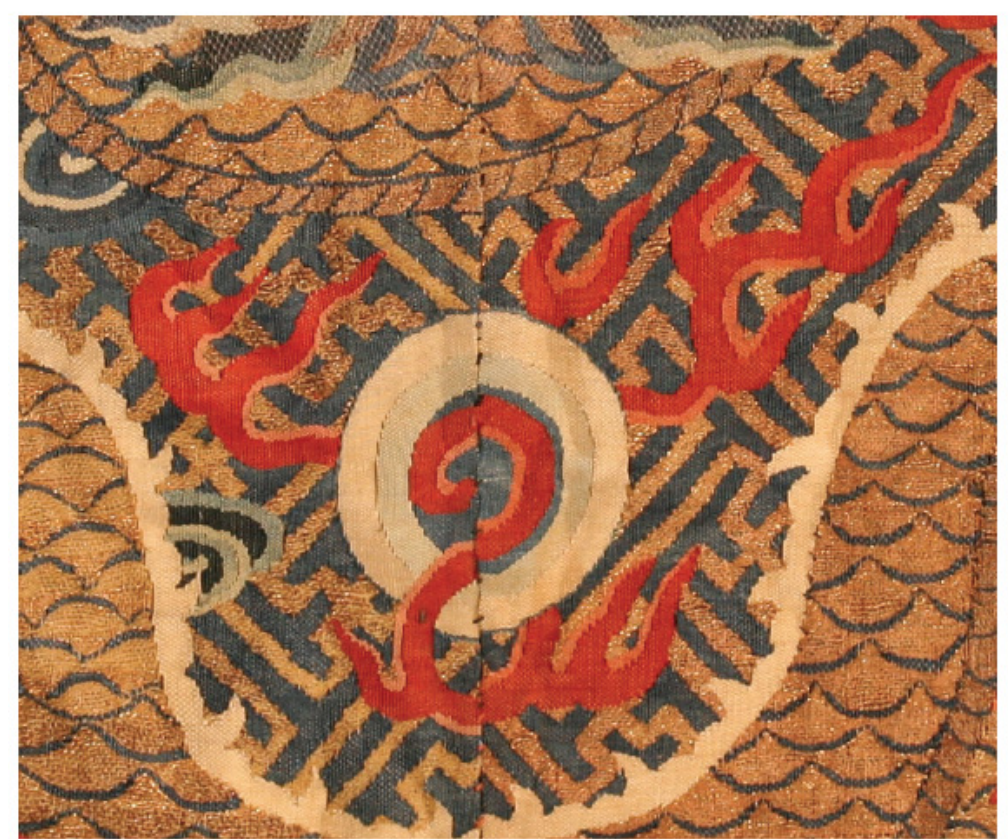

Figure 5. Flaming pearl on the robe front. Picture of Dragon robe is housed University of Hawaii at Manoa Costume Collection.

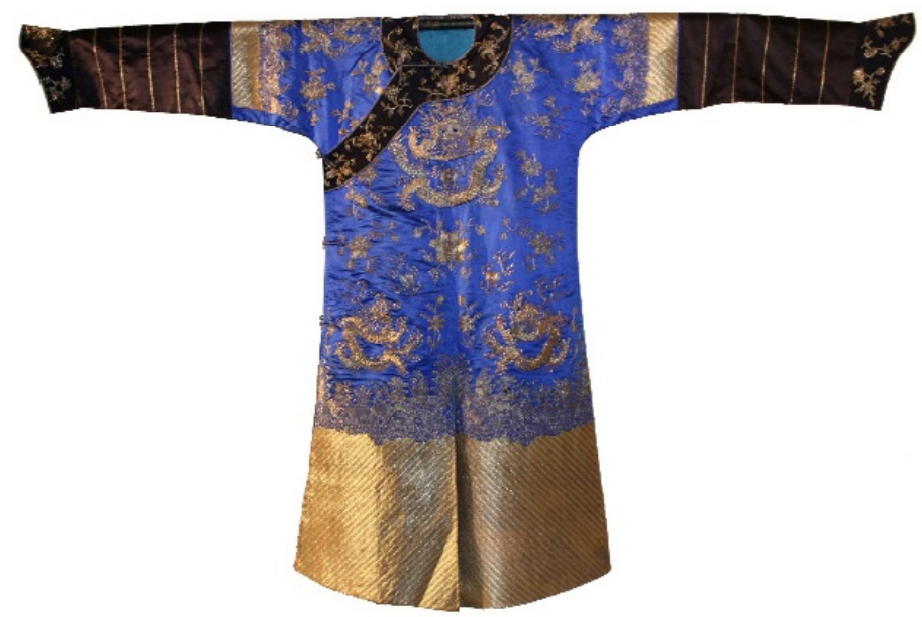

Figure 6. Dragon robe (Jifu). Picture of Dragon robe is housed University of Hawaii at Manoa Costume Collection.

Many details of the University of Hawaii's blue silk dragon robe with gold-couched motifs reflect yin-yang harmony, from the use of colored threads to the orientation or size of the details. Gold embroidered dragon and floral motifs decorate the University of Hawaii's blue silk dragon robe. The heavy weight of the garment indicates that the threads are made with pure gold, which suggests that the original owner was either wealthy or received this the garment as a special gift from the imperial family. Upon closer examination, the gold motifs are couched onto the plain weave silk with either red or yellow thread. The juxtaposition of the yellow and red threads suggest yin and yang, respectively.

The motifs are constructed with five-ply gold-wrapped yellow and red threads applied to silk-satin using yellow and red couch embroidery stitches. Yellow is associated with the earth and yin element. The golden tone 
specifically represents wealth and happiness, and was a color traditionally used in imperial service. Red is associated with the yang element; it is regarded as a lucky color to the Chinese, and is used frequently for its associations with good fortune and joy. When both colors are used in together, they are doubly auspicious.

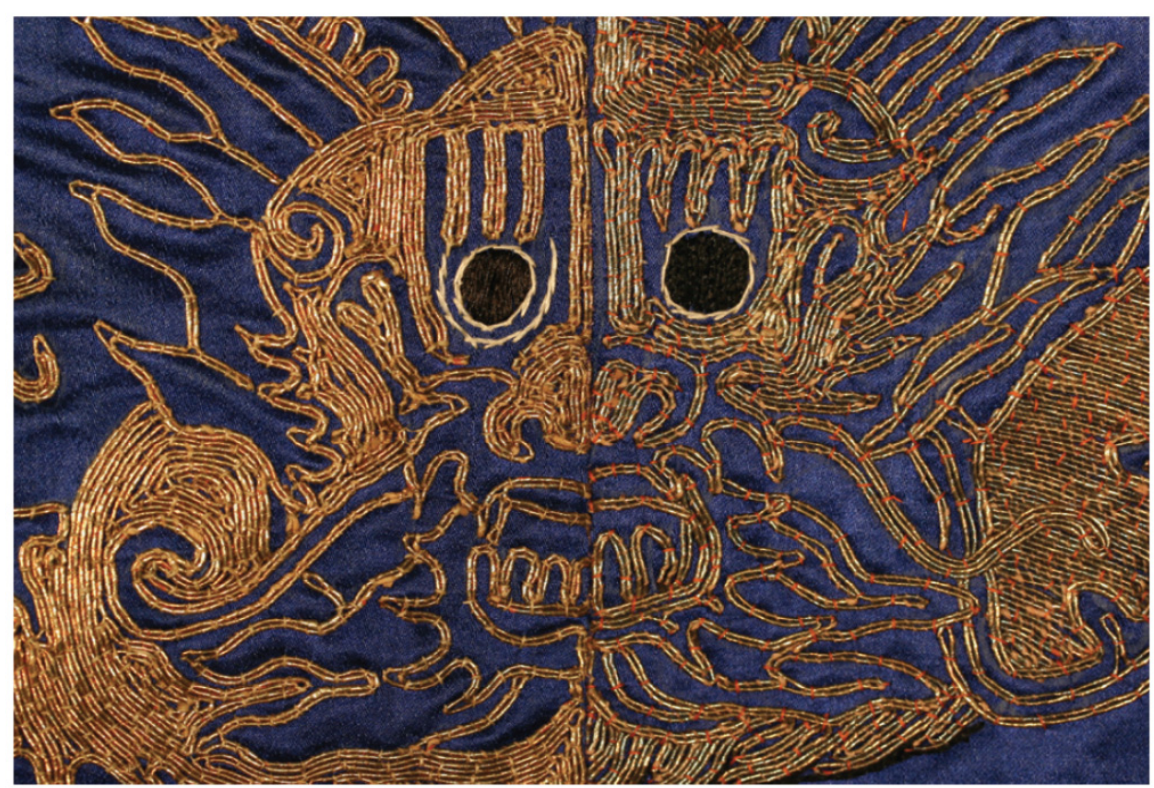

Figure 7. Two-color tone of couch stitches and eyes indicated a yin/young face. Picture of Dragon robe is housed University of Hawaii at Manoa Costume Collection.

The seated dragon on the center of the bodice is the chief symbol for the yin-yang concept as it uses both colors of couching thread. However, only one color is used on either half of the dragon and flaming pearl design in order to exemplify the separation of the yin and yang forces. On the lower bodice and shoulders, each walking dragon and flaming pearl uses either yellow or red in association with color of the threads used on the seated dragon. In Figure 8, the dragon body demonstrates two-toned color and design: yellow couched stitches without shade represent yin, orange couched stitches with shadow on the bottom of dragon body represent yang. The dragon's eyes and the edge of its body are the only sections of the robe to feature black thread. The yang dragons with red couch stitch are highlighted with short-long stitch in black thread on one edge of dragon's body and beard. All eyes are filled with black satin stitch, encircled with off-white rear back stitch.

One eye on the front-facing dragon is made with the vertical satin stitch while the other eye is made with bias satin stitch. The off-white satin stitch highlight around the one eye is formed into a complete circle. The eye is highlighted with two lines of satin stitch. The inner line completely surrounds the eye while the outer line is half complete. As with the dragon's eyes, there are further design differences between the yin or yang dragons in places such as the hair, nose, mouth, claws, and patterns of the scales.

The pheasant and flower basket motifs also share the purple/blue color difference as the flaming pearl and ribbons (Dusenbury, 2004). The beak and legs of the pheasants are woven in purple on the left and blue on the right. The flower basket, like the flaming pearl is located in the center front bodice and is halved by the center front-line. The flower basket handle on the left side is woven with purple while the handle on the right is woven with blue. 


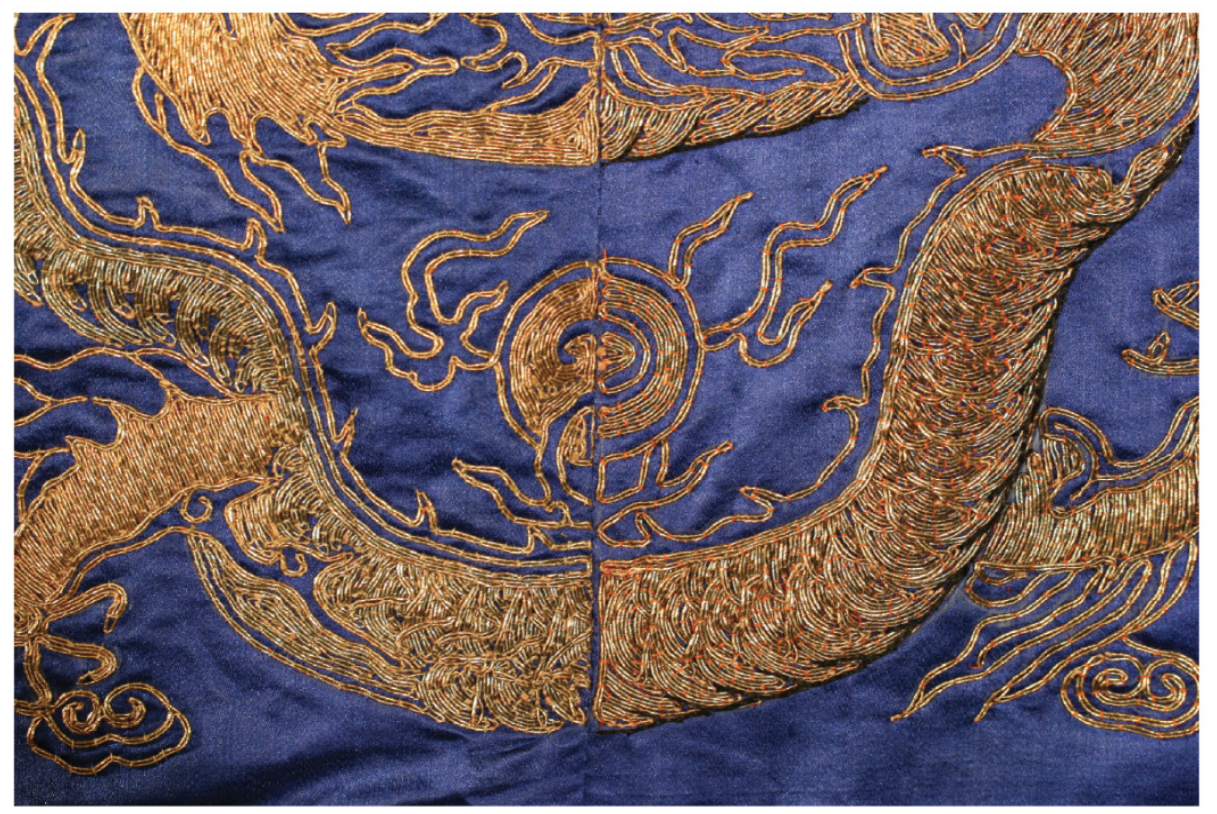

Figure 8. Yellow couched stitches without shade present yin; orange couched stitched with shadow on the bottom of dragon body represent yang. Picture of Dragon robe is housed University of Hawaii at Manoa Costume Collection.

Below the center dragon, a yellow gourd is located near each lower claw of the dragon's foot. Like the pheasant motifs, the gourd design varies when compared to either left of right. The differences occur in the color of the gourds and also the ribbons around them. The gourd on the right side of the bodice is dark yellow with five ribbons for yang and the gourd on the left is light yellow with four ribbons for $y$ in.

The two-color tone motifs which play a significant role in the dragon robes housed in the UHM costume collection to suggest yin and yang are the bat and lotus motifs woven in either red or blue. Red is the color associated with yang and blue is the color associated with yin. The color variations of these motifs are not dependent on the side on which they are located on the robe like the previous motifs mentioned above. Here, both red and blue bat and lotus motifs are dispersed throughout the textile design.
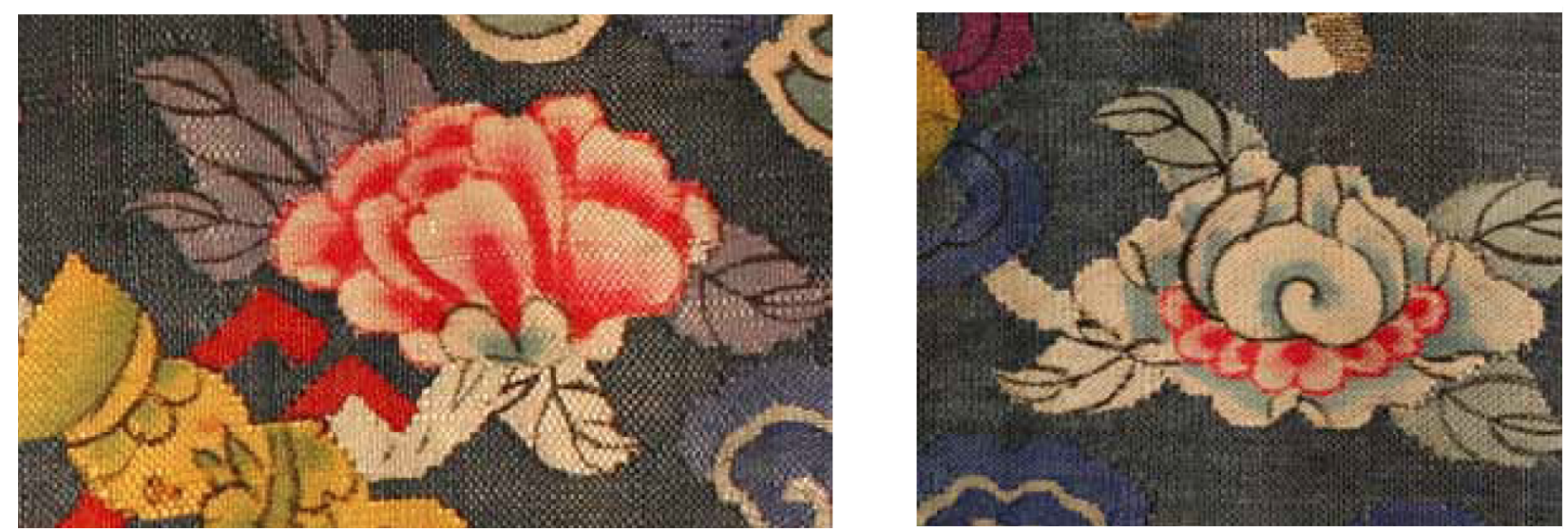

Figure 9. Red lotus and blue lotus. Picture of Dragon robe is housed University of Hawaii at Manoa Costume Collection.

Not only are the red and blue color tones individually prescribed to yin-yang meaning, the color difference also brings additional meaning to the bat and lotus motifs on the robe. Red bats are considered special omens of 
enormous fortune. Furthermore, red bats depicted upside-down imply that the blessings have arrived to the dynasty. On the other hand, the red lotus means "enormous peace". Blue bat and blue lotus motifs imply service to the Qing dynasty and loyalty to the emperor, and are only worn on the garments of non-imperial officials and other nobles.
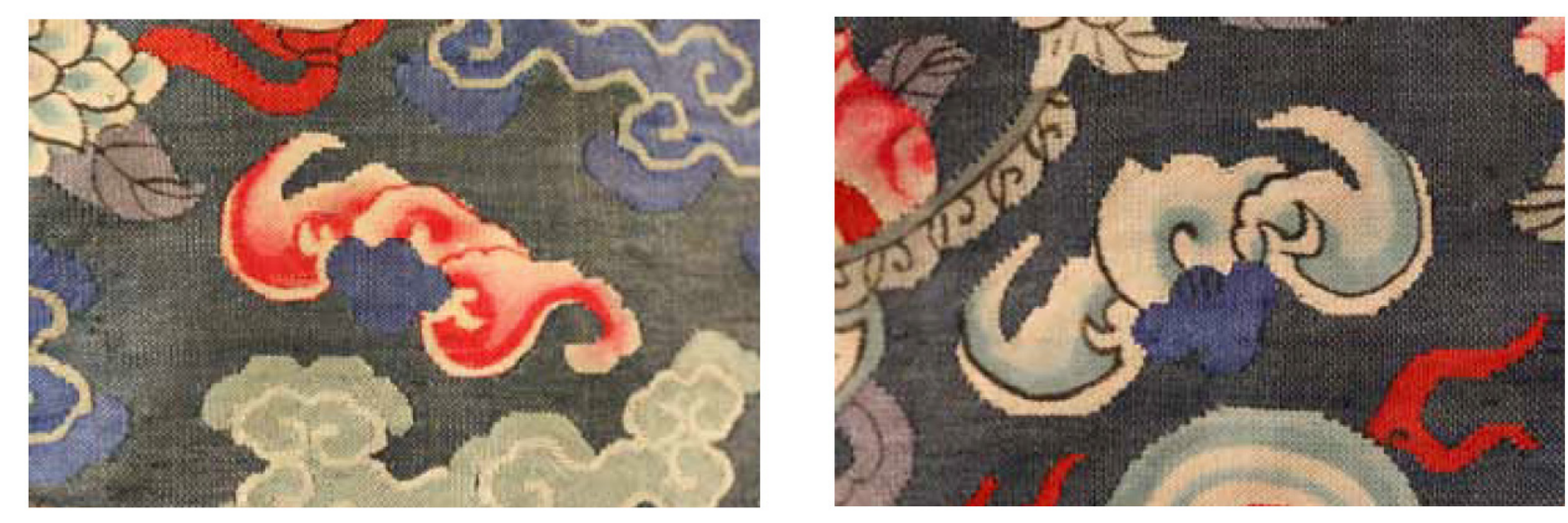

Figure 10. Red bat and blue bat. Picture of Dragon robe is housed University of Hawaii at Manoa Costume Collection.

In addition, the lotus motifs differ in color and design. The designs of the lotuses range from buds to full blossoms. The flower buds are woven in either red or blue and the blossoms are woven with both colors. The alternation between blossom and flower bud and red and blue depicts yin-yang activity.

\section{Discussion and Conclusion}

The Qing dynasty imperial dragon robes from the University of Hawaii Costume Collection are examples in which yin-yang has been applied to express the observance of cosmic harmony in Chinese philosophy. The design and details of these robes actively seek to express yin-yang philosophy. Yin-yang design aimed towards replicating harmony and balance in nature. It also acted to define the imperial relationship to the cosmos and grand scheme of the universe. Based on natural cosmic occurrences, such as day and night, yin and yang extends to explain other dichotomic concepts, such as cold and hot, light and dark and fullness and emptiness.

Chinese textiles are valuable to study due to the great workmanship and highly developed skills put forth by their construction present by the complexity of the motifs and delivery of their intended meanings. Court costume has been a valuable resource for researchers to explore how the ancient Chinese used textiles to demonstrate political power and social rank and reconstruct historical Chinese textile technology. While the structure and some symbols of court dress, such as the Twelve Symbols of Sovereignty, have been inherited in the previous dynasties, other symbols, such as the Eight Buddhist Treasures and Immortals of Taosim were adopted in Qing court costume. Since the Qing dynasty, the thoughtful application of yin-yang philosophy has been embedded into many of these design motifs to enhance their traditional meaning.

Studies have shown that Chinese court costume reveals the complexity of social arrangement, such as imperial kinship and civil or military official codes depicted by its construction and symbology, as seen in yin-yang costume design. The Qing dynasty imperial kosse (i.e., tapestry) dragon robes from the University of Hawaii Costume Collection are examples of sophisticated Chinese textiles technique, court ranking and cultural application. The design and symbols suggest rank and merits specific to the wearer, as specified by official 
court regulations in the Da-Qing-Hui-Dien, in order to maintain the organization of the Qing dynasty official system.

The Qing dynasty dragon robes from the University of Hawaii Costume collection are both examples of the highly-decorative weaving technique of Chinese slit-tapestry, or kosse (i.e., tapestry). Kosse were frequently used to create complex motifs in Qing dynasty court costume (Haig \& Shelton, 2006; Gao, 1992). The contrasting motifs of yin-yang have been sensitively reflected in these robes due to the vivid color contrasts made possible by the weave patterns. Through the use of two-color tone (i.e., red and yellow; red and blue) shifts and duo-shape patterns (i.e., fully open eye and half opened eye) in the symbolic motifs, the kosse dragon robes are able express yin-yang and signal traits intended to honor the wearer. In present times, the affluence of traditional Chinese culture is remains preserved by these priceless Qing imperial costumes.

\section{References}

Cammann, S. (1944). The development of the Mandarin square. Harvard Journal of Asiatic Studies, 8(2), 71-130.

Cammann, S. (1952). China's dragon robes. New York: The Ronald Press.

Capon, E. (1970). Chinese court robes in the Victoria and Albert Museum. Fosh \& Cross.

Cheng, D. C. H. (2008). Interpretations of yang in the yijing commentarial traditions. United States: Blackwell Publishing Limited.

Dusenbury, M. M. (2004). Flowers, dragons \& pine trees: Asian textiles in the Spencer Museum of Art. New York: Hudson Hills Press.

Fenarld, H. E. (1946). Chinese court costumes. Toronto: Royal Ontario Museum of Archaeology.

Gao, H. (1992). Chinese textile designs. NY: Viking.

Garrett, V. M. (1987). Images of Asia: Traditional Chinese clothing. Hong Kong: Oxford University Press.

Garrett, V. M. (2007). Chinese dress: From the Qing dynasty to present. Rutland, VT: Tuttle Press.

Haig, P., \& Shelton, M. (2006). Threads of gold: Chinese textiles, Ming to Ch'ing. Schiffer Pub Limited.

Hall, C., Lee, C. L., Zhoa, F., John, E. V., Diana, C., Szan, T., \& Wong, H. L. (2006). Power Dressing: Textiles for rulers and priests from the Chris Hall Collection. Singapore: Asian Civilizations Museum.

Ho, J. A. (1974). Class notes by author. Lecture on the Book of Yi. University of Chinese Culture, Taipei, Taiwan. Class notes. Jackson, B., \& David, H. (1999). Ladder to the Clouds: Intrigue and Tradition in Chinese Rank. Berkeley, CA: Ten Speed Press. Lattimore, O. (1935). Manchuria cradle of conflict. New York: The Macmillan Company.

Lin, S. (2008). Chinese court dress design principles. Context, 15, 12-15.

Lin, S. (2013). Booklet, Qing Imperial Costume Design: Yin-Yang Philosophical Influence. Department of Family \& Consumer Sciences, University of Hawaii.

Lin, S. (2015). Exploring Design Theory in Chinese Dragon Robes. Costume Society of America's Annual Meetings and Symposium, 24, San Antonio, TX.

Mattern, J. (1981). Silk as ceremony: The dress of China in the late Ch'ing dynasty period (1959-1911). Fiber Arts, 8(3), 75-76.

Michael, F. (1942). The origin of Manchu rule in China. Baltimore: The John Hopkins Press.

Scott, A. C. (1958). Chinese costume in transition. Singapore: Donald Moore.

Shih, H. Y. (1977). Textile finds in the People's Republic of China. In V. Gervers (Ed.), Studies in textile history (pp. 305-331). Toronto, Canada: Royal Ontario Museum.

Tortora, P. G., \& Merkel, R. S. (1996). Fairchild's dictionary of textiles. Fairchild Publications.

Vollmer, J. (1977a). Clothing and the politics of conquest: Manchu court costume in China. Rotunda, 10(2), 40-48.

Vollmer, J. (1977b). In the presence of the dragon throne: Ch'ing dynasty costume (1644-1911) in the Royal Ontario Museum. Canada: Royal Ontario Museum.

Vollmer, J. E. (1983). Decoding dragons: Status garments in Ch'ing dynasty China. University of Oregon: Museum of Art.

Welch, P. (2013). Chinese art: A guide to motifs and visual imagery. Tuttle Publishing.

Zhoa, X. B. (1989). Chinese ancient clothing history. Taipei: Nain-Tan Book.

Zhou, X., \& Gao, C. (1988). 5000 years of Chinese costumes. Hong Kong: China books \& Periodicals, Inc.

大清會典 (Da-Qing-Hui-Dien) (1690-1899). The Qing Dynasty Standard, Qing Dynasty politics system to accommodate the nationality. 